\author{
Stanisław Jaśkowski
}

\title{
ON THE DISCUSSIVE CONJUNCTION IN THE PROPOSITIONAL CALCULUS FOR INCONSISTENT DEDUCTIVE SYSTEMS*
}

Two-valued discussive systems (cf. [1]) of the propositional calculus $\mathbf{D}_{\mathbf{2}}$ can be enlarged by means of the discussive conjunction $\wedge_{d}$. To this end instead of the definition $\mathbf{M}_{\mathbf{2}}$ def. 1 from [1] we need to posit the following definition

$\mathbf{M}_{2} \operatorname{def} 1.1$

$$
p \wedge_{\mathrm{d}} q:=p \wedge \diamond q
$$

After this emendation we can simplify the definition of the discussive equivalence by replacing $\mathbf{M}_{\mathbf{2}}$ def. 2 by the following:

$\mathbf{M}_{2} \operatorname{def} 2.1$

$$
p \leftrightarrow_{\mathrm{d}} q:=\left(p \rightarrow_{\mathrm{d}} q\right) \wedge_{\mathrm{d}}\left(q \rightarrow_{\mathrm{d}} p\right)
$$

The metalogical theorem 1 (cf. [1], p. 68) remains valid in the following generalized form: Each thesis $A$ of the two-valued classical calculus $\mathbf{L}_{2}$ containing no other symbols than $\rightarrow, \leftrightarrow, \vee$ or $\wedge$ is transformed into thesis of the discussive calculus $\mathbf{D}_{\mathbf{2}}$ by replacing in $A$ functors $\rightarrow$ by $\rightarrow_{\mathrm{d}}$, $\leftrightarrow$ by $\leftrightarrow_{\mathrm{d}}$, and $\wedge$ by $\wedge_{\mathrm{d}}$, respectively.

* Editorial note. Read at the meeting of section A, Societatis Scientiarum Torunensis, 23th March 1949. Published in Polish under the title "O koniunkcji dyskusyjnej w rachunku zdań dla systemów dedukcyjnych sprzecznych", in: Studia Societatis Scientiarum Torunensis, Sectio A, Vol. I, no. 8, Toruń 1949, pp. 171-172. 
The proof of the theorem contains no essential change in comparison with the proof of the metalogical theorem 1 from my original paper [1]. We must only use theorems 5-7 of $\mathbf{M}_{\mathbf{2}}$ (cf. [1], p. 68) plus a new thesis of $\mathbf{M}_{\mathbf{2}}$ :

$\mathbf{M}_{2} 7.1$

$$
\diamond\left(p \wedge_{\mathrm{d}} q\right) \leftrightarrow(\diamond p \wedge \diamond q) .
$$

The law of the inconsistency for the discussive conjunction is the following thesis of $\mathbf{D}_{\mathbf{2}}$ :

$\mathbf{D}_{2} 4.1$

$$
\neg\left(p \wedge_{\mathrm{d}} \neg p\right),
$$

whereas the refuted conjunctive form [i.e., Duns Scotus Law - J.P.] is

$\left(\right.$ non $\left.\mathbf{D}_{\mathbf{2}}\right) 3.1$

$$
\left(p \wedge_{\mathrm{d}} \neg p\right) \rightarrow_{\mathrm{d}} q
$$

despite the fact that previously we had an analogous theorem for the usual [classical - J.P.] conjunction, which in my previous paper [1] is denoted by $\mathbf{D}_{2} 5$ (cf. [1], p. 69).

\section{References}

[1] Stanisław Jaśkowski "Rachunek zdań dla systemów dedukcyjnych sprzecznych", Studia Societatis Scientiarum Torunensis, Sectio A, Vol. I, No. 5, Toruń, 1948, pp. 57-77. The first English translation "Propositional calculus for contradictory deductive systems", by O. Wojtasiewicz, appeared in Studia Logica, Vol. XXIV (1969), pp. 143-157. The second version, with a few modifications, including changing of notation, "A propositional calculus for inconsistent deductive systems", is published in this volume, pp. $35-56$.

(translated by Jerzy Perzanowski)

\section{Comments of the translator}

1. The main result of this very short, but quite important, note is its main metatheorem that $\mathbf{D}_{\mathbf{2}}$ in fact contains the full positive part of the classical logic plus observation ( $\mathbf{M}_{\mathbf{2}}$ 7.1) that with the new notion of discussive conjunction Jaśkowski's basic transformation is remarkably simplified, becoming a common homomorphism. 
2. Moreover, on the ground of a modified $\mathbf{D}_{\mathbf{2}}$ we have quite a lot of nice new theorems, such as the law of inconsistency $\left(\mathbf{D}_{\mathbf{2}} 4.1\right)$. Indeed, on the basis of $\mathbf{M}_{\mathbf{2}}$ (i.e., S5) we have that:

$$
\begin{aligned}
\neg\left(p \wedge_{\mathrm{d}} \neg p\right) & \dashv \vdash \diamond(\neg(p \wedge \diamond \neg p)) \\
& \dashv \vdash(p \rightarrow \square p) \\
& \dashv \vdash(\square p \rightarrow \diamond \square p) .
\end{aligned}
$$

3. It is clear that on the ground quite close to the modified $\mathbf{D}_{\mathbf{2}}$ we can define quite a lot of new discussive connectives, including discusive negation:

$$
\neg_{\mathrm{d}} p:=\diamond \neg p .
$$

Indeed, in $\mathbf{S 5}$ it is easy to verify that

$$
\begin{aligned}
\neg_{\mathrm{d}} p & \leftrightarrow \diamond \neg p \\
& \leftrightarrow((p \rightarrow p) \wedge \diamond \neg p) \\
& \leftrightarrow\left((p \rightarrow p) \wedge_{\mathrm{d}} \neg p\right) .
\end{aligned}
$$

Also reversely,

$$
\begin{aligned}
\left(p \wedge_{\mathrm{d}} q\right) & \leftrightarrow(p \wedge \diamond q) \\
& \leftrightarrow(p \wedge \diamond \neg \neg q) \\
& \leftrightarrow\left(p \wedge \neg_{\mathrm{d}} \neg q\right) .
\end{aligned}
$$

Discussive conjunction and discussive negation are thereby interdefinable on the ground $\mathbf{S 5}$, hence they are closely interconnected in the modified version of $\mathbf{D}_{\mathbf{2}}$.

4. Of course, we have

$$
\begin{aligned}
\neg \neg_{\mathrm{d}} p & \rightarrow p \\
\neg p & \rightarrow \neg_{\mathrm{d}} p, \\
p & \rightarrow \neg_{\mathrm{d}} \neg p, \\
\neg_{\mathrm{d}} \neg_{\mathrm{d}} p & \rightarrow p .
\end{aligned}
$$

But not reversely. For in $\mathbf{S 5}$ we easily obtain

$$
\diamond p \leftrightarrow \neg_{\mathrm{d}} \neg p,
$$

whereas

$$
\begin{aligned}
\square p & \leftrightarrow \neg \neg_{\mathrm{d}} p, \\
& \leftrightarrow \neg_{\mathrm{d}} \neg_{\mathrm{d}} p .
\end{aligned}
$$

